\title{
Methods for Determining the Amount of Colloidal Material in Soils ${ }^{1,2}$ [PRELIMINARY PAPER]
}

\section{By Charles J. Moore, William H. Fry and Howard E. Middleton}

BurEaU of Solls, U. S. Department of Agriculture, Washington, D. C.

The study of soil solutions and the aqueous extracts of soils has engaged the attention of this Bureau for some time past. Investigators in this field have realized for a long while that the aqueous extracts frequently contain considerable colloidal material which renders them opalescent, and that it is quite impossible to clarify such solutions by any ordinary means of filtration. Very recently Anderson and Fry completed a preliminary study of the solid phases obtained by the evaporation of certain soil extracts. In order to obtain sufficient material they found it necessary to work up from 500 to $2000 \mathrm{lbs}$. of soil. The amount of colloidal material obtained from so large a quantity of extract was, of course, considerable, and it possessed such striking properties that some time was devoted to the study of it.

\section{METHOD OF PREPARATION ${ }^{3}$}

A battery of barrel-type churns was used for stirring up the soil with water. Twenty-five lbs. of soil were placed in each churn and $125 \mathrm{lbs}$. of pure distilled water added. The churns were rotated for several hours and then allowed to remain at rest for $24 \mathrm{hrs}$. before the supernatant liquid was siphoned off into well-tinned milk cans. The next step was to pass the turbid liquid through a Sharples centrifuge. While this is a continuous process, it is calculated that each portion of the liquid was subjected to the force of 17,500 gravity for at least $5 \mathrm{~min}$. The liquid issuing from the centrifuge was usually quite opalescent with colloidal material, which was next separated from the dispersing medium by means of batteries of PasteurChamberlain filter tubes (Bogie F). The clear filtrate was concentrated in steam kettles for other researches. The colloidal material collected on the outside of the tubes in a slimy, sticky mass which soon clogged the filters. However, it was easily removed by blowing air into the tubes. We have given the name "ultra clay" to this material.

The ultra clay was purified in many instances by dialysis. This process proved very slow and was finally given up, and the purification was carried out by stirring the colloid up with distilled water and drawing the water off by means of clean filter tubes. This method was very satisfactory,

\section{COMPOSITION AND PROPERTIES}

The chemical composition of ultra clay varies considerably. We are convinced that it is a mixture of colloids, consisting mainly of the hydrated silicate of aluminium, and containing varying amounts of ferric hydroxide, silicic acid, organic matter, and possibly aluminium hydroxide. There are always present small but varying amounts of calcium, magnesium, potassium, and sodium-whether chemically combined

1 Received January 31, 1921.

2 Published by permission of the Secretary of Agriculture.

- Method developed by R. O. E. Davis, L. B. Olmstead and M. S. Anderson. or physically adsorbed has not yet been determined.

When ultra clay is suspended in water, it gives every evidence of being a true colloid. Under the ultramicroscope, it appears as droplets of an amberyellow color and shows the Brownian movement to a very marked degree. When very dilute solutions of electrolytes are allowed to diffuse under the cover glass on the slide, the Brownian movement is at once arrested. When suspensions are concentrated, much flocculation occurs. The addition of any electrolyte or of alcohol will, of course, have the same effect. When the thick mass is diluted or the coagulating material is removed by washing, a free suspension of the colloid is again obtained. If the colloid is very thoroughly dried on the water bath, it resuspends in water very slowly. The dry material is resinous and of an amber-yellow color.

Clay soils that have been thoroughly elutriated, as in the mechanical analysis of soils, lose much of their plasticity. The ultra clay, on the other hand, is very plastic when moist, and exceedingly sticky. Certain experiments have been carried out to determine the adhesive properties of ultra clay. The results recorded in the following table show that, up to 10 per cent, ultra clay is a much stronger binding agent than portland cement. However, this is true only when the material is dry. Briquets cemented together with ultra clay go to pieces very readily when thoroughly moistened.

Crushing Stranath of Briguers

(Briquets $25 \mathrm{~mm}$. high and $25 \mathrm{~mm}$. in diameter, made up with 18 per cent of moisture under $1800 \mathrm{lbs}$, pressure per sq. in. and dried at $100^{\circ} \mathrm{C}$.) Cementing Portland Cecil Susquehanna Commercial $\begin{array}{ccccc}\text { Material } & \text { Cerment } & \text { Ultra Clay } & \text { Ultra Clay } & \text { Karalin } \\ \text { Per cent } & \text { Kilos } & \text { Kilos } & \text { Kilos } & \text { Kilos }\end{array}$

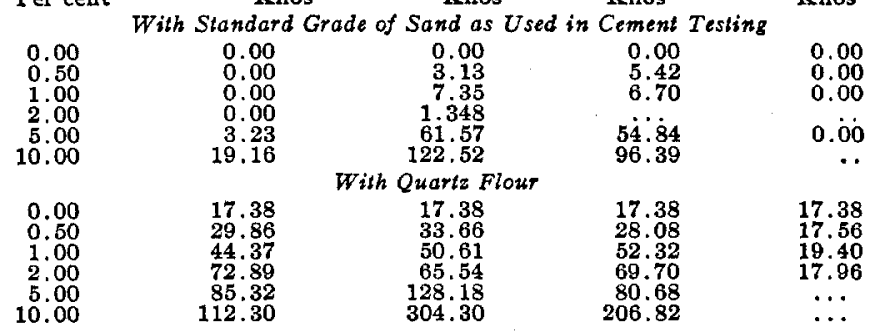

It seems evident, therefore, that ultra clay is the principal binding material of the soil, giving it plasticity, cohesiveness, or hardness, according to the moisture content. The recognition of these important properties shows the fundamental relation the material bears to tillage and to certain engineering problems, including subgrades in road construction. The possibility of finding a means to control certain of these properties offers a field of research, with the promise of results of economic importance to agriculture and to engineering.

\section{ABSORPTION OF AMMONIA}

That soils freely absorb gases is a very well-known fact, generally looked upon as a surface phenomenon, characteristic to some extent of all finely divided sub- 
stances. It seems just as reasonable to assume that the absorptive properties of soils are due to the colloids they contain, and it was with the view of discovering some characteristic property of colloids, not possessed by the other components of soils, which could be made the basis of a method for determining their amount in different soils, that the following work was undertaken. U1tra clay was dried in an electric oven at $110^{\circ} \mathrm{C}$. for $24 \mathrm{hrs}$. It was immediately transferred, while still hot, to a Schwartz U-tube, and weighed, and the tube placed in a train of drying apparatus. The Schwartz tube was then immersed in boiling water and thoroughly evacuated with an oil pump. The $\mathrm{U}$-tube was next placed in an ice bath, and dry ammonia gas was passed over the ultra clay until it would absorb no more under a pressure of one atmosphere. The current of gas was then shut off, and the apparatus was allowed to stand for $1 \mathrm{hr}$. to make sure that equilibrium had been reached, as shown by a manometer attached to the U-tube. The next step was to draw off the ammonia and collect it in a train of absorption apparatus filled with a saturated boric acid solution. When a good deal of ammonia had been drawn off, the U-tube was again placed in boiling water and the residual ammonia displaced with a current of air. The ammonium borate solution was titrated with $0.1 N$ sulfuric acid, using methyl orange as indicator. AMOUNT OF EXPOSED SURFACE-At the outset it seemed desirable to investigate to some extent the influence on the absorption of ammonia of surface actually exposed. For this purpose ultra clay obtained from Cecil clay loam was divided into two parts. One part was carefully granulated so that all the particles would pass through a $1-\mathrm{mm}$. sieve, and the other half was made into cylindrical masses under a pressure of 3000 lbs. These cyliaders measured $5 \mathrm{~mm}$. in diameter and $5 \mathrm{~mm}$. in height. They were extremely compact and presented exceedingly smooth surfaces. Both samples were air-dried and oven-dried as above described. The following results were obtained:

Each cc. of Cecil ultra clay, granulated, absorbed $111.1 \mathrm{cc}$. $\mathrm{NH}$,

Each cc. of Cecil ultra clay, cylinders, absorbed $110.3 \mathrm{cc}$. $\mathrm{NH}$.

These values are averages of several independent and fairly closely agreeing determinations. The hard, compact pellets apparently absorbed ammonia as readily and to practically the same extent as the loose, incoherent material. The absorption and evolution of ammonia in no way disintegrated the pellets.

SUSQUEHANNA CLAY SOII-Since the compactness or looseness of the material made no difference, the determinations on ultra clay obtained from Susquehanna clay soil ${ }^{1}$ were made on the granulated material only, and the following result is the average of five good determinations:

Each cc. of Susquehanna ultra clay absorbed $93.05 \mathrm{cc}$. $\mathrm{NH}_{3}$

1 For the sake of completeness the mechanical analysis of the Susquehanna clay soil is appended:

$\begin{array}{lllr}\begin{array}{c}\text { Diameter } \\ \text { Mm. }\end{array} & \begin{array}{l}\text { Conventional } \\ \text { Names }\end{array} & \begin{array}{c}\text { Weight } \\ \text { Grams }\end{array} & \text { Percentages } \\ 2 \quad-1 & \text { Fine gravel } & 0.000 & 0.00 \\ 1 \quad-0.5 & \text { Coarse sand } & 0.000 & 0.00 \\ 0.5-0.25 & \text { Medium sand } & 0.025 & 0.50 \\ 0.25-0.1 & \text { Fine sand } & 0.105 & 2.10 \\ 0.1-0.05 & \text { Very fine sand } & 0.815 & 16.30 \\ 0.05-0.005 & \text { Silt } & 2.263 & 45.30 \\ 0.005-0 & \text { Clay } & 1.793 & 35.90\end{array}$

In all of the above determinations from 7 to $10 \mathrm{~g}$. of the colloid were used, and the volume was calculated from the weight and the absolute specific gravity, which in the case of the Cecil was found to be 2.76 and the Susquehanna 2.64 .

It may be worthy of note that on the whole the Susquehanna colloid proved to be a weaker binding material than that obtained from the Cecil soil, and that its ability to absorb ammonia was less, to roughly the same extent.

EFFECT OF HEAT-The above results show conclusively that soil colloids possess a remarkable capacity for absorbing ammonia. If the other components of the soil should absorb none, it would be necessary only to determine the capacity of the colloid and of the soil itself in order to calculate the quantity of colloid in a given soil. Light would be thrown upon the point in doubt by heating the colloid to a temperature at which its nature is entirely destroyed. The Cecil colloid was selected for heat treatment, because it could be readily obtained in very pure condition. Later Susquehanna clay soil was treated in practically the same manner, except that in some instances the intermediate temperature stages were slightly different. The heating was carried out as follows: A large quantity of pellets was made up as above described and placed in sixteen silica crucibles. The crucibles were then put into a large, specially constructed, automatically controlled electric oven. The temperature was carefully checked by means of a good pyrometer. At the end of $24 \mathrm{hrs}$.' heating, two of the crucibles were removed and the temperature was stepped up to the next higher stage and maintained for $24 \mathrm{hrs}$, when the next two crucibles were removed. This procedure was continued to the end. As soon as the samples were removed from the furnace, ammonia absorption determinations were made, and the following results were obtained:

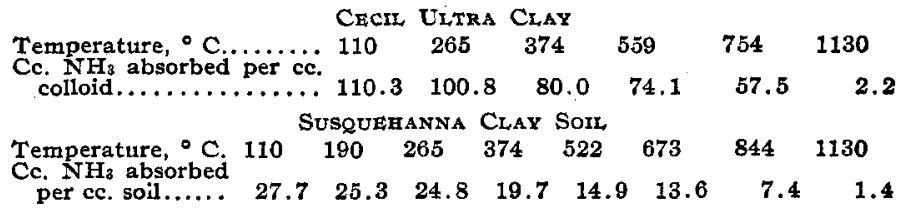

The assumption that the absorption of ammonia by soils is due to the colloids they contain seems to be borne out by the above results. There is evidence of progressive destruction of colloids that is not connected with the process of dehydration, as will be shown later on. A careful microscopic examination of the material heated to $1130^{\circ} \mathrm{C}$. showed no evidence of fusion even on sharp edges. There was some change of color and a very decided shrinkage.

CALCULATION OF RESULTS-In the light of the above results, the following calculations seem to be justified:

Susquehanza ultra clay, heated to $110^{\circ}$, absorbed $93.0 \mathrm{cc} . \mathbf{N H}_{3}$

Susquehanna clay soil, heated to $110^{\circ}$, absorbed $27.7 \mathrm{cc}$. $\mathrm{NH}_{3}$

Susquehanna clay soil, heated to $1130^{\circ}$, absorbed $1.4 \mathrm{cc} . \mathrm{NH}_{3}$

Deducting $1.4 \mathrm{cc}$. $\mathrm{NH}_{3}$ absorbed by material, presumably not colloidal, from 27.7 cc. absorbed by the unaltered soil leaves $26.3 \mathrm{cc}$. absorbed by the colloid of the soil. Therefore, if the pure colloid absorbs $93.0 \mathrm{cc} . \mathrm{NH}_{3}$ and there is sufficient colloid in the soil 
to absorb 26.3 cc. $\mathrm{NH}_{3}$, the colloidal content of the soil must be 28.3 per cent.

\section{ABSORPTION OF DYESTUFFS}

That filtration through soil clarifies water and removes many colored bodies from it has been known for a great many years. It seems very probable that soil colloids play an important part in this phenomenon. A large number of experiments were carried out with colored inorganic and organic substances with the view of testing the ability of soil colloids to absorb them. It was found that ultra clay removed from true solution none of the inorganic substances tested, such as salts of copper, cobalt, and nickel, but that it was highly absorbent of organic dyestuffs. Many dyes were tested, and while the ultra clay absorbed them in large measure, in every instance except one some factor developed that interfered with the quantitative estimation along the line we wished to pursue, viz., the placing of a weighed sample of ultra clay in water containing an excess of dye, the coagulation and removal of the colloid after a time, and the estimation of the quantity of dye left in solution by comparison with a standard dye solution. Usually a change of shade made such a comparison impossible. In our experience, malachite green oxalate proved to be best suited to our method, thus confirming Ashley's experience in his work on clays. Ashley found that lime decolorized the malachite green by combining with the oxalate radical and forming the insoluble calcium oxalate. This is to be expected in view of the fact that the carbonate radical is apparentiy not able to combine with the pentavalent nitrogen atom of the quinone-like secondary benzene residue of the dye, resulting in the loss of the quinoid structure upon which the color of the dye depends. The writers attempted to remedy this difficulty by adding an excess of oxalic acid, but any appreciable excess of the acid over and above that required to precipitate the calcium altered the shade and diminished the intensity of the color. It was found, however, that a considerable excess of sodium oxalate had no effect upon the dye. After the difficulty with the calcium had been overcome, variations in the size of samples used with a constant initial amount of dye showed that a distribution effect was playing a part in determining the amount of dye absorbed, as the following results indicate:
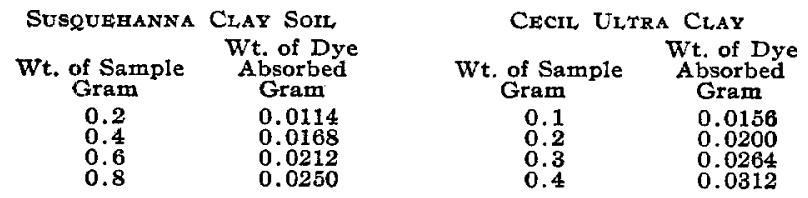

All of the above samples had been heated for $72 \mathrm{hrs}$. at $265^{\circ}$ C. A second series run with Cecil ultra clay heated at $110^{\circ}$ gave similar results.

In the next series the weights of the samples taken were the same as above, but instead of adding a constant initial amount of dye, the amount added was such as to leave an approximately constant quantity in solution after the sample had absorbed all it would under the conditions. The following results were obtained:

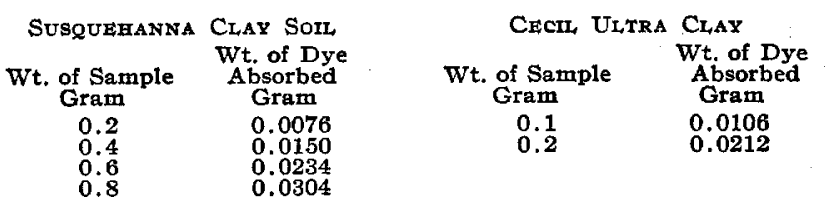

The above determinations prove conclusively that comparable results can be obtained only when certain conditions of dye concentration are carefully observed.

DESCRIPTION OF METHOD-A gram sample is shaken up with $40 \mathrm{cc}$. of distilled water in a large test tube. A $0.1 N$ sodium oxalate solution is then added until there is a slight excess over the amount required to precipitate the calcium. The tube is corked and placed in an end-over-end shaking machine for 15 min. to insure complete precipitation. The suspension is next treated with a certain small excess of 0.2 per cent malachite green solution. The mixture is made up to definite volume $(70 \mathrm{cc}$.) with distilled water, and the tube again placed in the shaking machine for $1 \mathrm{hr}$. Five cc. of normal sodium chloride solution are now added to flocculate the colloidal material, and the tube is centrifuged in a large mechanical analysis machine until the supernatant liquid is perfectly clear. This liquid is compared in a Duboscq colorimeter with a standard solution of dye to which have been added all of the reagents contained in the other.

Two complete series of Susquehanna clay soil samples were heated as previously described under absorption of ammonia; in fact, the samples for this work were heated in the same furnace and at the same time with the clay pellets in order to be sure the conditions were exactly the same. The dye absorption determinations were then made as above described, with the following results:

\section{Susoughanna Clay Sold}

( $1 \mathrm{~g}$. of soil, weighed after heating, was used in all determinations)

\begin{tabular}{|c|c|c|c|c|c|}
\hline Temp., & First Series- & $\mathrm{I}$ & & Average & mple \\
\hline $\begin{array}{r}110 \\
190 \\
265 \\
374 \\
322 \\
673 \\
844 \\
1130\end{array}$ & 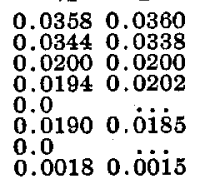 & $\begin{array}{l}0.0352 \\
0.0344 \\
0.0203 \\
0.0204 \\
0.0194 \\
0.0197 \\
0.0105 \\
0.0019\end{array}$ & $\begin{array}{l}0.0358 \\
0.0342 \\
0.0197 \\
0.0198 \\
0.0196 \\
0.0197 \\
0.0111 \\
0.0019\end{array}$ & $\begin{array}{l}0.0357 \\
0.0342 \\
0.0200 \\
0.0200 \\
0.0195 \\
0.0192 \\
0.0108 \\
0.0018\end{array}$ & $\begin{array}{l}0.000 \\
0.003 \\
0.005 \\
0.010 \\
0.055 \\
0.064 \\
0.065 \\
0.065\end{array}$ \\
\hline
\end{tabular}

Calculation of amount of colloid in Susquehanna clay soil from data obtained by dye absorption method:

Susquehanna ultra clay, heated to $110^{\circ} \mathrm{C}$., absorbs $0.1196 \mathrm{~g}$. dye

Susquehanna clay soil, heated to $110^{\circ} \mathrm{C}$, absorbs $0.0357 \mathrm{~g}$. dye

Susquehanna clay soil, heated to $1130^{\circ} \mathrm{C}$, absorbs $0.0018 \mathrm{~g}$. dye

Deducting the $0.0018 \mathrm{~g}$. dye absorbed by material, presumably not colloidal, from $0.0357 \mathrm{~g}$. dye absorbed by the unaltered soil leaves $0.0339 \mathrm{~g}$. dye absorbed by the colloid of the soil. Therefore, if the pure colloid absorbs $0.1196 \mathrm{~g}$. dye and there is sufficient colloid in the soil to absorb $0.0339 \mathrm{~g}$. dye, the colloidal content of the soil must be 28.3 per cent. This is exactly the same result as was obtained by the ammonia absorption method.

Calling the maximum absorption of ammonia and of dyestuff 100 , and expressing the other values as percentages of the maximum in each instance, we obtain the accompanying graphs, showing the diminution in the ability of the soil to absorb these substances as the temperature is raised. 
It will be observed that the ammonia absorption graph slopes very uniformly, while in the dye absorption graph there is a very decided break at $190^{\circ}$ and

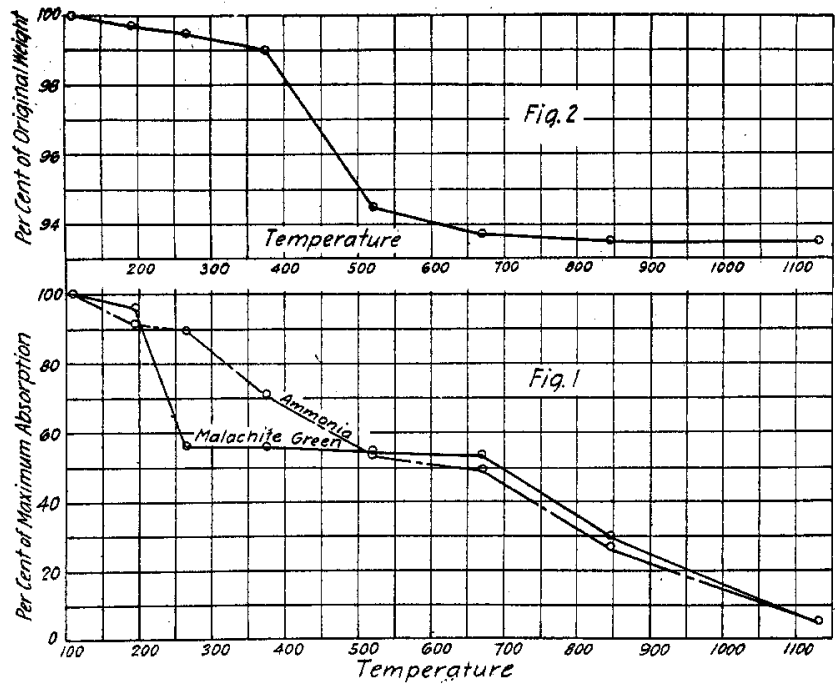

another at $673^{\circ}$. The loss in weight graph (in reality a rough dehydration curve, there being present only 0.13 per cent of organic matter) shows no apparent relationship to the other two. This indicates that it is not the process of dehydration alone that causes the diminution in ability to absorb ammonia and dye, but that the heat actually alters the nature of the absorbing material.

COMPOSITE SAMPLES-The next point investigated was to ascertain whether composite samples made by mixing soil in which the colloid was completely destroyed and the pure colloid in definite proportions would actually absorb the quantity of dye calculated on the basis of data obtained for the two components.

\begin{tabular}{ccccc}
$\begin{array}{c}\text { Susquehanna } \\
\text { Soil }\end{array}$ & $\begin{array}{c}\text { Cecil } \\
\text { Colloid }\end{array}$ & $\begin{array}{c}\text { Susquehanna } \\
\text { Colloid }\end{array}$ & \multicolumn{2}{c}{$\begin{array}{c}\text { Absorption of Dye } \\
\text { Wt. }\end{array}$} \\
Wt. & Wt. & $\ldots$ btained Calculated \\
$0.6614\left(1130^{\circ}\right)$ & $0.3385\left(110^{\circ}\right)$ & $\ldots$. & 0.0388 & 0.0370 \\
$0.7271\left(1130^{\circ}\right)$ & $0.2729\left(110^{\circ}\right)$ & $0.1859\left(110^{\circ}\right)$ & 0.0304 & 0.0300 \\
$0.8146\left(110^{\circ}\right)$ & $\ldots \ldots$ & 0.0496 & 0.0513
\end{tabular}

The results indicate the correctness of the assumption that the colloids of the soil are the only active absorbing components of the soil.

In order to gain still further evidence on this point, samples of Susquehanna soil heated to $844^{\circ} \mathrm{C}$., which showed considerable absorptive power, and samples of the same material heated to $1130^{\circ} \mathrm{C}$., which showed practically none, were ground to impalpable powders in the dry state and then ground for a long while under water. The size of the samples was the same, and the two were ground to exactly the same extent. When grinding was completed, the samples were shaken up with a large quantity of distilled water in tall cylinders. After 3 wks. of standing undisturbed, the supernatant liquid of the sample heated to $844^{\circ} \mathrm{C}$. was quite cloudy and an ultramicroscopic examination and other tests proved that the material was truly colloidal, while the other sample gave a perfectly clear supernatant liquid after 3 days' standing. We failed absolutely to find any evidence of colloidal material in this sample.
Briquets were next made of Susquehanna clay soil, which had been previously heated to $844^{\circ}$ and to $1130^{\circ}$, and the crushing strength tested and compared with tests given by the original soil. The following results were obtained:

Kilos Required
to Crush

The results indicate the correctness of the statement that ultra clay is the principal binding material of soils. It is not a question of minute particles sticking together, but of the actual presence of a powerful binder, the nature of which is destroyed by the application of heat. Pure quartz flour, in a much finer state of subdivision than the soil, heated to $1130^{\circ}$ gave a test of 8 kilos, as compared to 17 kilos given by the unheated material. It is difficult to conceive how the application of $1130^{\circ}$ could change this material in any direction other than the destruction of the small amount of colloidal silicic acid it contains.

\section{SUMMARY}

1-A method has been described for separating large quantities of soil colloids from soil.

2-The effect of heat upon pure soil colloids and upon Susquehanna clay soil has been studied and discussed.

3-Two methods for determining the quantity of colloidal material in soil have been developed, one based upon the absorption of a dry gas by a dry colloid, and the other upon the absorption of dye from true solution by an aqueous suspension of the material. The fact that methods so entirely different in nature give the same results seems to justify confidence in them. There still remains the possibility that the pure colloid we are able to separate from the soil does not possess the same absorptive ability as the whole colloid of the soil. If the values found for the pure colloids separated from the soil are higher than for the whole colloid of the soil, our methods give low results, and vice versa. The possibility is remote, but the point will be further investigated.

4-The methods have been applied to one soil only. The investigation must be extended to a number of other soils before anything definite can be said of their general utility. If success is met with, they will be used in connection with the finding of means to control soil colloids, which have been shown to be the natural binding material of the soil-a factor which largely determines physical properties.

\section{Dr. Chandler Receives National Institute of Social Sciences Medal}

Another honor came to Dr. Charles Frederick Chandler on May 19, 1921, when he received the gold medal of the National Institute of Social Sciences, for his service in the field of sanitation. In his presentation address, Dr. M. T. Bogert characterized Dr. Chandler as:

Nestor of American chemical industry and its foremost exponent whether in the lecture hall or the patent court, beneficent, public-spirited citizen, for sixty-five years he has served humanity with tireless energy and skilfully directed zeal, ever eager to find new ways in which to make his life of greater usefulness to his fellows. 